\title{
Penambahan Sistem Pendingin Heatsink Untuk Optimasi Penggunaan Reflektor Pada Panel Surya
}

\author{
Andi Pawawoi* dan Zulfahmi \\ Jurusan Teknik Elektro, Fakultas Teknik, Universitas Andalas \\ *e-mail: andi.pawawoi@eng.unand.ac.id
}

\begin{abstract}
Abstrak - Alternatif yang dapat dipilih untuk meningkatkan daya keluaran photovoltaik yakni dengan menambah intensitas cahaya yang diterima menggunakan reflektor. Namun apabila intensitas ditambah akan menyebabkan kenaikan temperatur yang ikut seiring dengan peningkatan intensitas cahaya, hal ini akan menurunkan daya keluaran photovoltaik. Untuk mengoptimalkan penggunaan reflektor pada photovoltaik perlu ditambahkan sistem pendingin. Tulisan ini bertujuan untuk melihat pengaruh penambahan sistem pendingin Heatsink pada photovoltaik yang dilengkapi dengan reflektor. Heatsink ditempelkan pada seluruh sisi belakang panel, dan untuk memperkecil resistansi termal, maka antara panel dan Heatsink diisi dengan paste termal. Pengamatan dilakukan dengan membandingkan 2 sistem, yaitu: sistem photovoltaik menggunakan reflektor tanpa pendingin dan sistem photovoltaik menggunakan reflektor yang dilengkapi sistem pendingin Heatsink. Hasilnya menunjukkan bahwa bahwa dengan penambahan sistem pendingin photovoltaik yang dilengkapi reflektor diperoleh penurunan suhu rata-rata $18,26 \%$ dan peningkatan daya rata-rata sebesar $10,14 \%$ dibanding sistem photovoltaik yang dilengkapi reflektor tanpa sistem pendingin.
\end{abstract}

Kata kunci: Photovoltaik, temperatur, daya, dan sistem pendingin.

\begin{abstract}
An alternative to increase photovoltaic output power is by increasing the intensity of received light using a reflector. However, the added intensity will increase in the temperature, hence reduce the photovoltaic output power. To optimize the use of reflectors in photovoltaics, a cooling system (i.e. Heatsink) needs to be added. This paper aims to find out the effect of adding a Heatsink cooling system to photovoltaics that equipped with a reflector. Heatsinks are installed at the entire back side of the panel and filled with thermal paste. Observations were made by comparing the photovoltaic system using a reflector without cooling system and the photovoltaic system using a reflector equipped with a Heatsink cooling system. The results show that the photovoltaic with cooling system has $18.26 \%$ average temperature decrease and $10.14 \%$ average power increase if compared to a photovoltaic system equipped with a reflector without a cooling system.
\end{abstract}

Keywords: Photovoltaic, temperature, power, and cooling system.

\section{Pendahuluan}

Pengembangan teknologi Pembangkit Listrik Tenaga Surya (PLTS) mendapat banyak perhatian dewasa ini. Selain itu, posisi Indonesia yang terletak di garis Khatulistiwa, dengan penyinaran matahari di wilayah Indonesia $\pm 12 \mathrm{jam} / \mathrm{hari}$ menjadikan PLTS sebagai solusi menarik untuk tuntutan kebutuhan akan listrik [1-2].

Untuk memaksimalkan energi listrik yang dapat dihasilkan dari photovoltaik biasanya beberapa panel dipasang secara seri. Namun untuk merealisasikan hal tersebut dibutuhkan photovoltaik yang tidak sedikit, sedangkan harga photovoltaik dipasaran saat ini relatif mahal, sehingga membutuhkan investasi yang sangat besar.

Alternatif lain yang dapat dipilih untuk meningkatkan daya keluaran matahari adalah dengan menambah intensitas cahaya yang diterima panel dengan menggunakan reflektor, cahaya matahari dipantulkan dengan cermin ke panel, sehingga intensitas cahaya yang diterima panel bisa meningkat. Namun hal tersebut menyebabkan naiknya temperatur photovoltaik yang berdampak turunnya tegangan output sehingga output daya maksimum pun akan turun.

Upaya meningkatkan daya output photovoltaik adalah dengan menambahkan sistem pendingin, seperti pendingin dengan sirkulasi air 
menggunakan pompa [3] atau pendingin sirkulasi udara menggunakan blower[4]. Penggunaan Heatsink pada photovoltaik standar juga telah dilakukan [5]. Dua metode pertama dinilai kurang efektif karena harus menggunakan energi untuk sirkulasi air dan udara. Metode penggunaan Heatsink dengan aliran udara alami dinilai cukup efektif karena sederhana dan tidak memerlukan energi tambahan. Khusus untuk penggunakan sistem pendingin Heatsink pada photovoltaik yang dilengkapi reflektor sejauh ini belum pernah dilakukan.

Optimasi penggunaan reflektor pada photovoltaik dapat dilakukan dengan mengurangi peningkatan temperatur permukaan photovoltaik menggunakan sistem pendingin. Tulisan ini bertujuan untuk melihat pengaruh penambahan sistem pendingin Heatsink aluminium pada photovoltaik yang dilengkapi reflektor cermin. Heatsink ditempelkan pada bagian belakang photovoltaik [6].

\section{Karakteristik Photovoltaik}

Secara sederhana photovoltaik atau sering juga disebut sel surya terdiri dari persambungan bahan semikonduktor bertipe $\mathrm{p}$ dan $\mathrm{n}(\mathrm{p}-\mathrm{n}$ junction semiconductor) yang jika terkena sinar matahari maka akan terjadi aliran elektron, aliran elektron inilah yang disebut sebagai aliran arus listrik [6].

Berikut merupakan karakteristik dari panel surya [6 - 8] :

a. Karakteristrik daya, karakteistik ini merupakan kurva hasil perkalian arus dan tegangan, dibangun dari kurva V-I. Karakteristrik daya mempelihatkan daya keluaran yang bisa diberikan oleh phtovoltaik, terdapat sebuah titik maksimum yang disebut Maximum Power Point (MPP). Nilai daya pada MPP dinotasikan dengan $\mathbf{P}_{\text {MPP }}$, gambar 1.

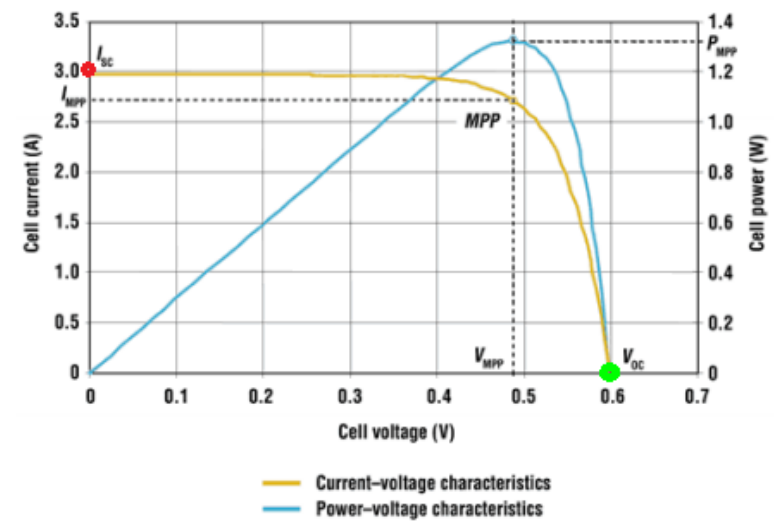

Gambar 1. Kurva MPP terhadap I-V

b. Karakteristrik I-V-Irradiance, adalah kurva yang memperlihatkan hubugan antara arus terhadap tegangan pada suatu nilai irradiance tertentu, gambar 2.

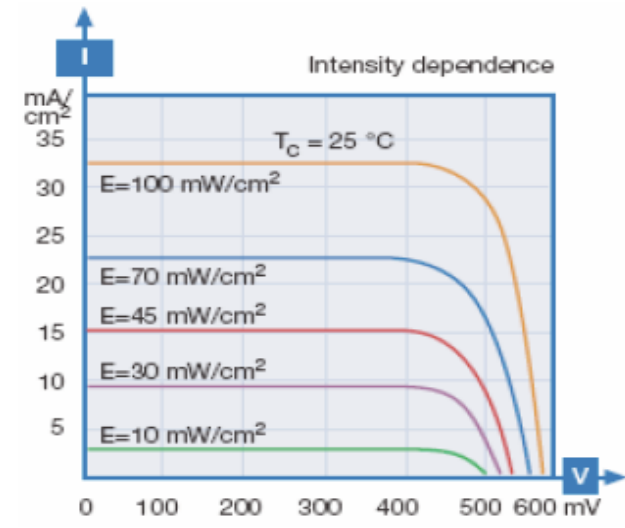

Gambar 2. Kurva I-V terhadap irradiance.

c. Karakteristrik I-V- temperatur, adalah kurva yang memperlihatkan hubungan antara arus terhadap tegangan pada temperatur tertentu, gambar 3.

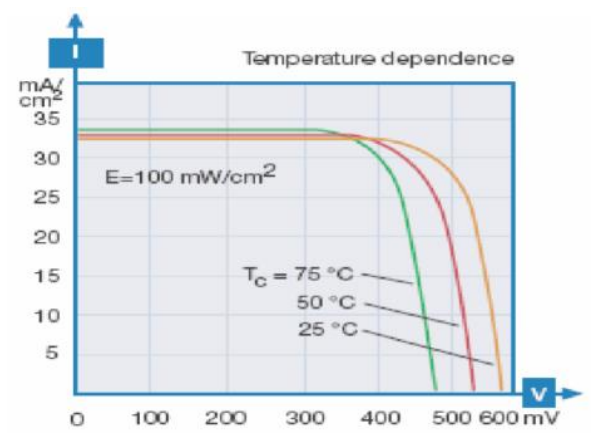

Gambar 3. Kurva I-V terhadap temperatur.

Photovoltaik bisa ditingkatkan efisiensinya dengan cara menambah reflektor. Reflektor pada photovoltaik berbentuk seperti cermin yang 
difungsikan sebagai pemantul dan pemfokus cahaya matahari ke photovoltaik. Pemantulan cahaya matahari akan membuat intensitas cahaya matahari lebih terkonsentrasi pada panel photovoltaik sehingga energi listrik yang dikeluarkan pada panel photovoltaik menjadi semakin besar. Meskipun penambahan reflektor pada photovoltaik dapat menambah performa panel sel surya, tetapi teknik ini ternyata juga memiliki kelemahan. Akibat dari pengonsentrasian intensitas cahaya ini adalah berimbas pada peningkatan temperatur photovoltaic. Peningkatan temperatur ini dapat menurunkan daya keluaran yang dihasilkan panel photovoltaik [9].

\section{Sistem Pendingin}

Sistem pendingin adalah suatu sistem yang berfungsi untuk menjaga temperatur suatu benda dalam kondisi yang ideal dengan cara memindahkan panas dari benda tersebut ke udara. Perpindahan panas pada dasarnya merupakan akumulasi perpindahan energi dari suatu tempat ke tempat lain. Perpindahan panas akan terjadi apabila ada perbedaan temperatur antara dua bagian benda. Panas akan berpindah dari temperatur tinggi ke temperatur yang lebih rendah [10].

Beberapa sistem pendingin yang umum digunakan antara lain: pendingin dengan hembusan udara, pendingin dengan aliran air, pendingin dengan Heatsink, dan sistem pendingin yang mengkombinasikan sistem-sistem tersebut.

Heatsink adalah plat-plat aluminium atau tembaga yang dibentuk memiliki sirip-sirip untuk memperluas bidang sentuh dengan udara atau fluida pendingin lainnya, seperti terlihat pada gambar 4. Sistem pendingin Heatsink bisa diaplikasikan tanpa menggabungkannya dengan sistem pendingin lain.

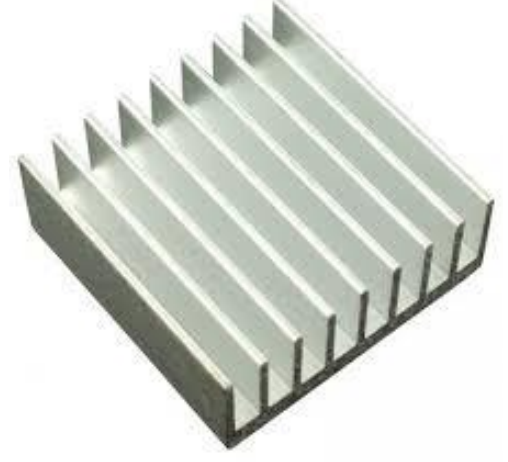

Gambar 4. Salah satu bentuk Heatsink dari bahan aluminium

\section{Metoda Penelitian}

Pengamatan dilakukan pada 2 sistem instalasi photovoltaik yang identik, seperti terlihat pada gambar 5 dan 6. Tipe dan ukuran photovoltaik dan reflektor kedua sistem sama, bedanya hanya bahwa salah satu dari sistem photovoltaik tersebut ditambah/dilengkapi dengan sistem pendingin Heatsink. Masing-masing sistem menggunakan photovoltaik $60 \mathrm{WP}$ dan 2 lembar reflektor cermin dengan lebar masing-masing sama dengan ukuran lebar photovoltaik $65,5 \mathrm{~cm} \times 77,5 \mathrm{~cm}$. Kedua sistem diset untuk bisa mengikuti pergerakan matahari.

Pengambilan data dilakukan secara bersamaan pada kedua sistem photovoltaik setiap 1 jam selama tiga hari cerah, dari jam 10:00 - 15:00. Setiap pengambilan data dilakukan dengan mengukur arus, tegangan, temperatur permukaan photovoltaik, dan irradiasi sinar matahari. Khusus pengambilan data arus dan tegangan, dilakukan dengan mengambil 11 data output dari kondisi hubung singkat hingga hubungan terbuka. Setiap pengambilan data ini dilakukan dalam selang waktu tidak lebih dari 2 menit untuk menghidari terjadinya perubahan intensitas cahaya matahari dan temperatur. Intensitas cahaya dipantau dengan Lux meter. Pengukuran temperatur dilakukan dengan Infrared Thermometer, alat ini dipilh karena memudahkan pengukuran temperatur permukaan photovoltaik cukup dengan menyorotkan sinar infrared dari alat ukur ini ke permukaan photovoltaik.

Untuk mengetahui optimasi penggunaan sistem pendingin pada sistem photovoltaik yang dilengkapi reflektor, maka data $\mathrm{P}_{\mathrm{MPP}}$ dan temperatur dari kedua sistem, akan dibandingkan. Titik daya maksimum $\left(\mathrm{P}_{\mathrm{MPP}}\right)$ diperoleh dari pengolahan data tegangan dan arus hasil pengukuran setiap jam.

\subsection{Sistem Pendingain Heatsink}

Sistem pendingin yang dipilih adalah pendingin menggunakan Heatsink berbahan aluminium seperti gambar 4, dengan aliran udara alami. Alasan pemilihan sistem pendingin ini karena mudah diaplikasikan dan tanpa membutuhkan energi untuk pendinginnya. Heatsink ditempelkan pada seluruh bagian belakang photovoltaik. Antara permukaan belakang photovoltaik yang luasnya $0,51 \mathrm{~m}^{2}$ dan Heatsink diberi paste thermal untuk meningkatkan 
konduktifitas panas kontak antara kedua bagian tersebut. Heatsink yang digunakan memiliki sirip dengan tinggi $1 \mathrm{~cm}$, tebal sirip $0,3 \mathrm{~cm}$ dan jarak antara sirip $0,5 \mathrm{~cm}$, luas total permukaan Heatsink termasuk sirip adalah $1,08 \mathrm{~m}^{2}$

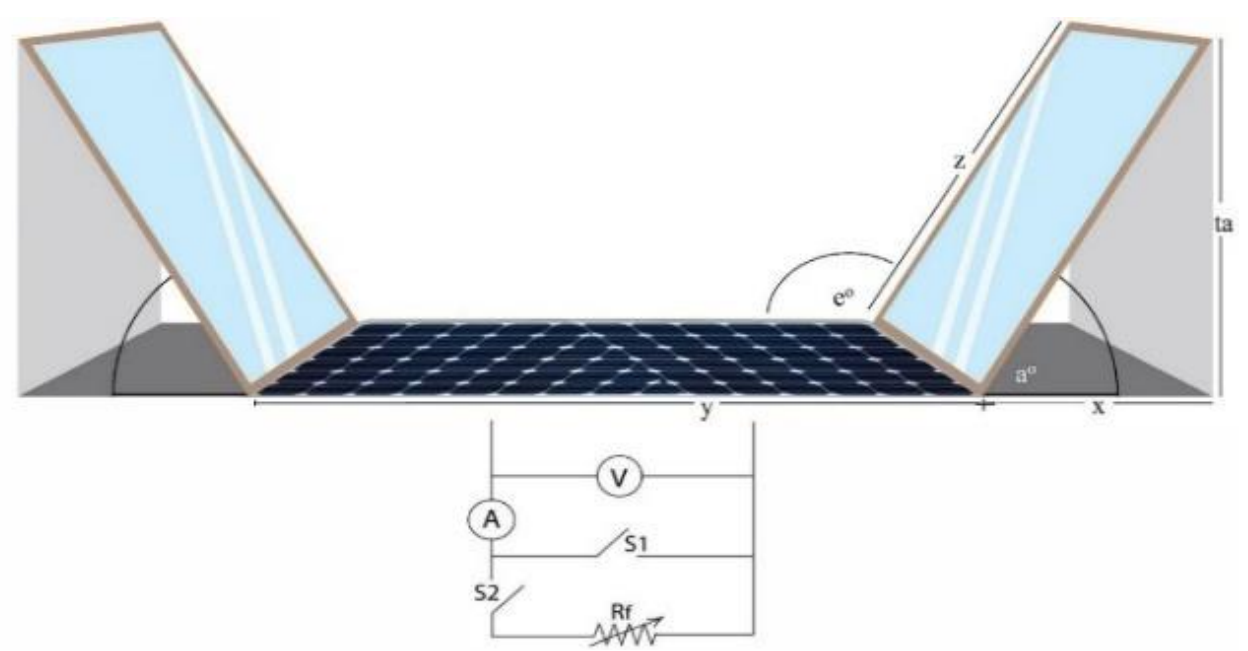

Gambar 5. Rangkaian photovoltaik dengan reflektor cermin tanpa sistem pendingin

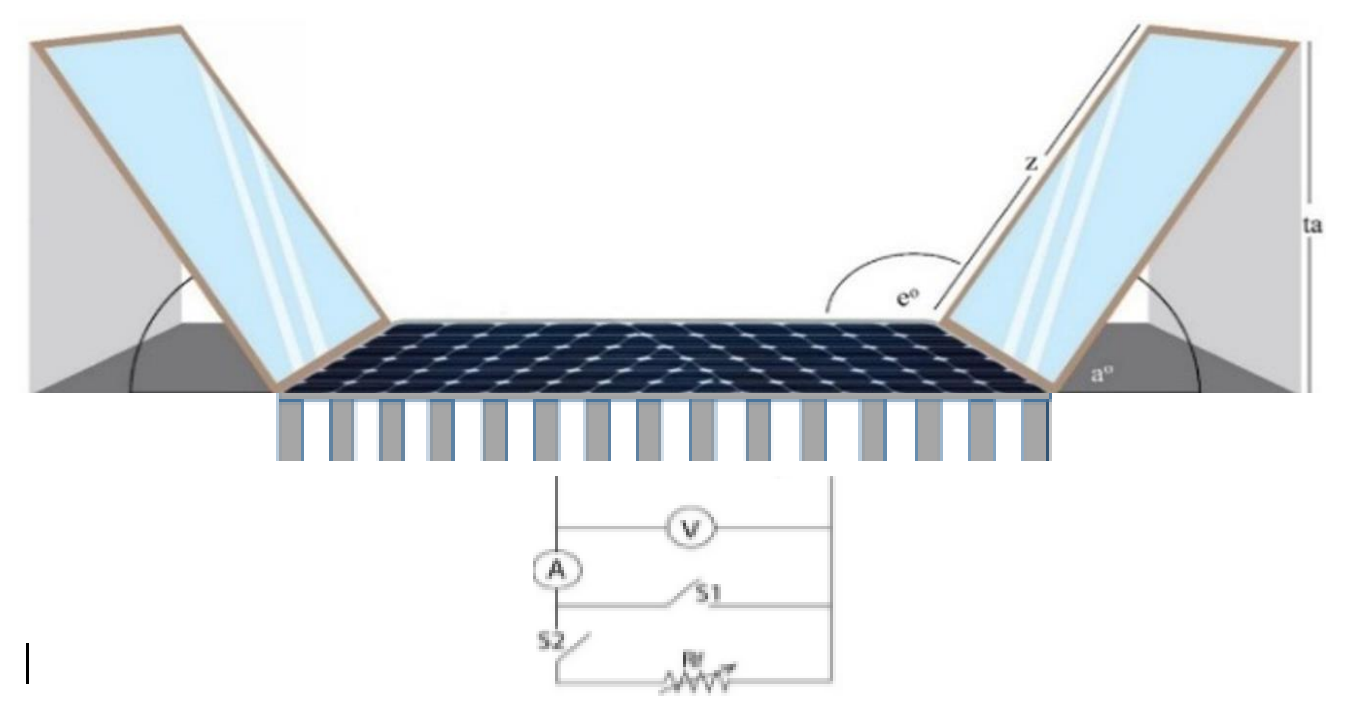

Gambar 6. Rangkaian photovoltaik dengan reflektor cermin dengan sistem pendingin.

\subsection{Analisa data Keluaran}

Untuk mengetahui rata-rata penurunan temperature digunakan persamaan :

$$
T_{\text {rata }}=\frac{T_{2}-T_{1}}{n}
$$

Untuk mengetahuit rata-rata peningkatan daya output, dihitung dengan persamaan :

$$
P_{\text {rata }}=\frac{P_{2}-P_{1}}{n}
$$

$T_{\text {rata }}$ : Penurunan tempratur rata-rata $\left({ }^{\circ} \mathrm{C}\right)$

$T_{l} \quad$ : Temperatur photovolaik dengan pendingin $\left({ }^{\circ} \mathrm{C}\right)$.

$T_{2} \quad$ : Temperatur photovoltaik tanpa pendingin $\left({ }^{\circ} \mathrm{C}\right)$

$P_{\text {rata }}:$ Peningkatan daya rata-rata $(\mathrm{W})$

$P_{l} \quad$ : Daya photovoltaik tanpa pendingin(W).

$P_{2} \quad$ : Daya photovoltaik dengan pendingin(W)

Dimana : 


\section{Hasil dan Pembahasan}

\subsection{Hasil Pengukuran Temperatur Photovoltaik.}

Hasil pengukuran temperatur permukaan photovoltaik yang dilengkapi reflektor dengan dan tanpa sistem pendingin selama 3 hari percobaan, masing-masing dari jam 10:00 hingga jam 15:00 diperlihatkan pada grafik gambar 6.

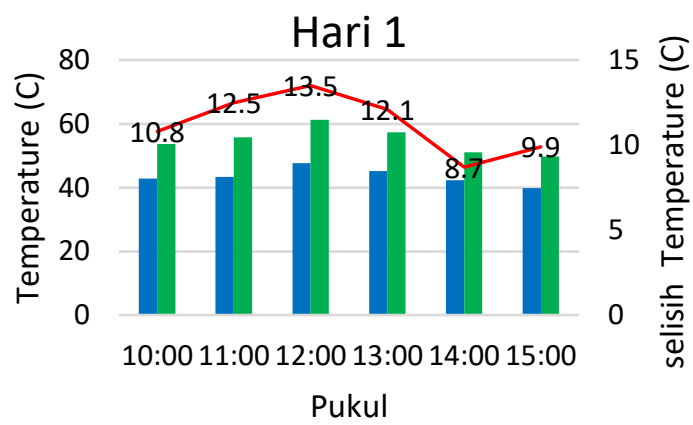

Hari 2

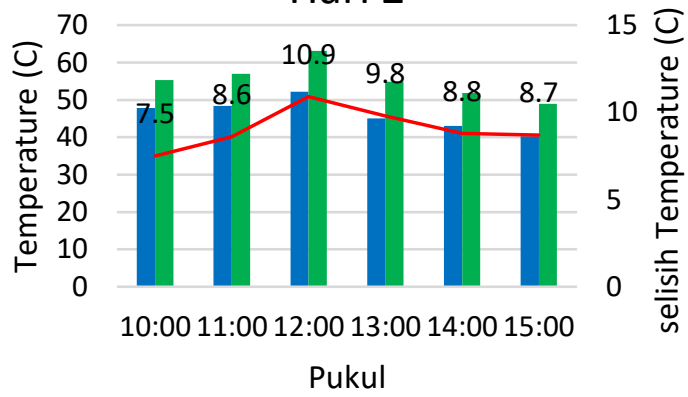

Hari 3

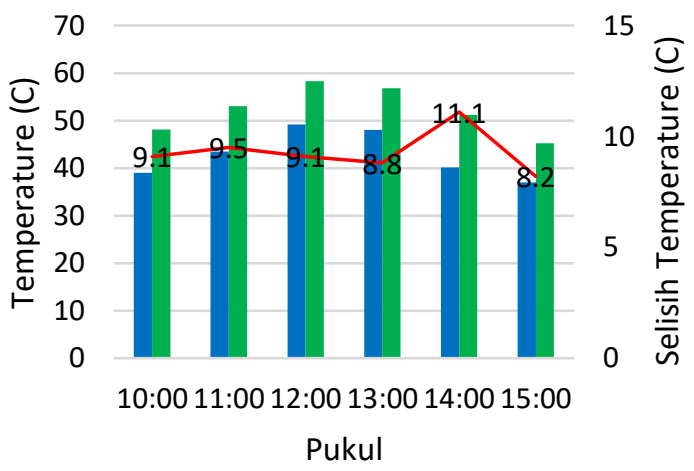

\footnotetext{
Kondisi Photovoltaic Dengan Heatsink (C) Kondisi Photovoltaic Tanpa Heatsink (C) Penurunan Temperature (C)
}

Gambar 6. Temperatur photovoltaik dengan dan tanpa pendingin

\subsection{Daya $\mathbf{P}_{\text {MPP }}$ Keluaran Photovoltaik Dengan dan Tanpa Sistem Pendingin.}

Daya $\mathrm{P}_{\mathrm{MPP}}$ keluaran photovoltaik yang dilengkapi reflektor dengan dan tanpa sistem pendingin selama 3 hari percobaan, masing-masing dari jam 10:00 hingga jam 15:00 diperlihatkan pada grafik gambar 7 .

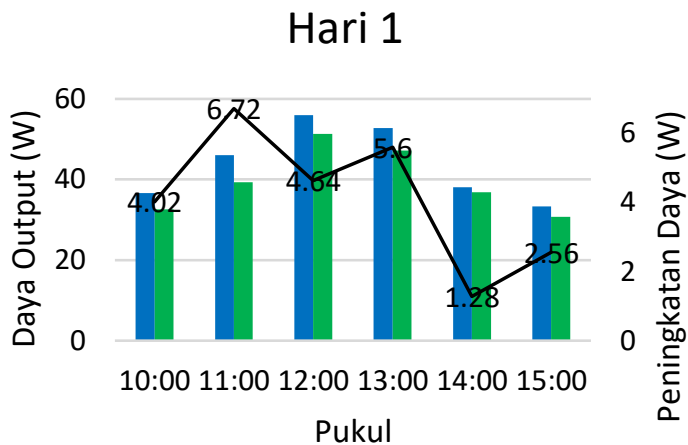

Hari 2

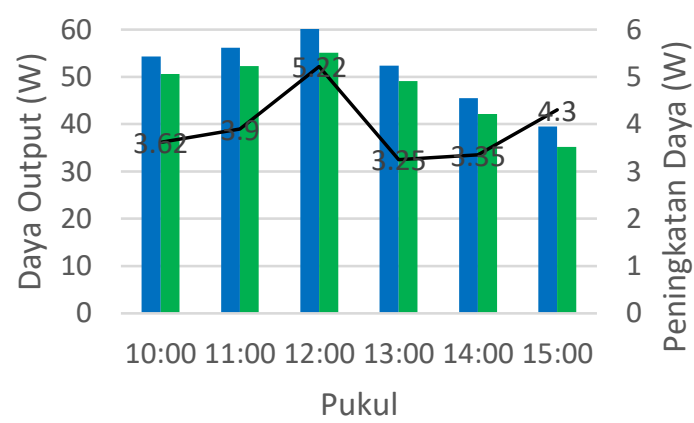

Hari 3

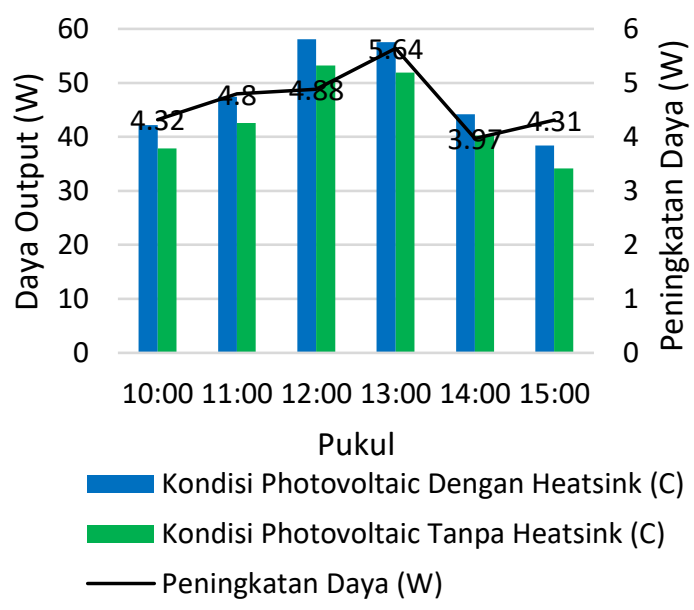

Gambar 7. Daya $\mathrm{P}_{\mathrm{MPP}}$ keluaran photovoltaik dengan dan tanpa pendingin 
Dari grafik di atas, daya yang dihasilkan oleh photovoltaik dengan sistem pendingin lebih besar dari pada daya yang dihasilkan oleh photovoltaik tanpa sistem pendingin.

\subsection{Pembahasan}

Penambahan pendingin pada sistem photovoltaik yang dilengkapi dengan reflektor cukup efektif menurunkan temperatur permukaan photovoltaik. Dari data hasil pengukuran selama 3 hari sebagaimana terlihat pada grafik gambar 6 dan dengan menggunakan persamaan (1) diperoleh rata-rata penurunan temperatur mencapai $9,87^{\circ} \mathrm{C}$ atau $18,26 \%$ dari sistem photovoltaik tanpa pendingin. Penurunan temperatur rata-rata per hari dapat dilhat pada tabel 1. Penurunan temperatur tertinggi tercatat $13,5^{\circ} \mathrm{C}$ dan terendah $7,5^{\circ} \mathrm{C}$

Sejalan dengan penurunan temperatur, daya $\mathrm{P}_{\mathrm{MPP}}$ keluaran photovoltaik mengalami peningkatan yang cukup signifikan. Dengan menggunakan persamaan (2) diperoleh rata-rata peningkatan daya $\mathrm{P}_{\mathrm{MPP}}$ selama 3 hari sebesar 4,24 $\mathrm{W}$, atau naik 10,14\% dari pada sistem photovoltaik tanpa pendingin. Peningkatan daya $\mathrm{P}_{\mathrm{MPP}}$ rata-rata per hari dapat dilhat pada tabel 1. Peningkatan daya tertingi sebesar 6,72 W (17\%) dan terendah 1,28 W (3\%). Selang perbedaan nilai tertinggi dan terendah cukup besar, hal ini disebahkan perubahan temperatur permukaan photovoltaik lebih lambat dibanding perubahan intensitas cahaya yang diterima. Sebagai contoh bila sesaat sebelum pengambilan data intensitas cahaya cukup tinggi yang menyebabkan temperatur permukaan photovoltaik cukup tinggi kemudian dilakukan pengambilan data dan pada saat itu intensitas cahaya berkurang secara cepat namun tidak bisa diikuti dengan perubahan temperatur permukaan photovoltaik yang cepat juga maka daya ouput photovoltaik cukup rendah.

Tabel 1. Peningkatan daya terhadap penurunan temperatur per ${ }^{\circ} \mathrm{C}$

\begin{tabular}{|c|c|c|c|}
\hline Hari Ke & $\begin{array}{c}\text { Peningkatan } \\
\text { Daya (W) }\end{array}$ & $\begin{array}{c}\text { Penurunan } \\
\text { Suhu }(\mathrm{C})\end{array}$ & $\begin{array}{c}\text { Peningkatan } \\
\text { Daya per }{ }^{\circ} \mathrm{C} \\
\left(\mathrm{W} /-1^{\circ} \mathrm{C}\right)\end{array}$ \\
\hline 1 & 4,14 & 11,25 & 0,368 \\
\hline 2 & 3,94 & 9,05 & 0,435 \\
\hline 3 & 4,65 & 9,3 & 0,500 \\
\hline Rata -rata & 4,24 & 9,87 & 0,434 \\
\hline
\end{tabular}

Karena setiap data dari kedua sistem diambil pada waktu yang sama dengan kondisi intensitas cahaya matahari yang sama, maka nilai peningkatan daya terhadap setiap penurunan temperature $1^{\circ} \mathrm{C}\left(\mathrm{W} /-1^{\circ} \mathrm{C}\right)$ dapat diperoleh dengan membandikan nilai peningkatan $\mathrm{P}_{\mathrm{MPP}}$ terhadap nilai penurunan temperatur masing-masing data. Nilai $\mathrm{W} /-1^{\circ} \mathrm{C}$ rata-rata per hari dan rata-rata selama 3 hari pengamatan diperlihatkan pada tabel 1. Dari tersebut terlihat nilai $\mathrm{W} / \mathrm{-}^{\circ} \mathrm{C}$ mendekati nilai yang sama dengan rata-rata sebesar $0,434 \mathrm{~W}$.

\section{KESIMPULAN}

1. Optimasi penggunaan reflektor cermin pada photovoltaik dengan menambahkan sistem pendingin Heatsink pada bagian belakang photovoltaik cukup efektif mengurangi temperatur permukaan dan meningkatkan daya keluaran photovoltaik

2. Rata-rata penurunan nilai temperatur pada photovoltaik yang dilengkapi reflektor dan sistem pendingin Heatsink mencapai 18,26\%. Terhadap photovoltaik dengan reflektor tanpa sistem pendingin

3. Rata-rata peningkatan nilai daya maksimum pada photovoltaik yang dilengkapi reflektor dan sistem pendingin Heatsink mencapai $10,14 \%$ terhadap photovoltaik dengan reflektor tanpa sistem pendingin.

4. Setiap penurunan temperatur sebesar $1{ }^{\circ} \mathrm{C}$ pada photovoltaik yang dilengkapi reflektor dan sistem pendingin Heatsink akan meningkatkan daya ouput sebesar 10,14\% terhadap photovoltaik dengan reflektor tanpa sistem pendingin.

\section{Ucapan Terima Kasih (Acknowledgement)}

Penulis bersyukur dan berterima kasih atas bantuan yang diberikan oleh Jurusan Teknik Elektro Fakultas Teknik Universitas Andalas untuk mendanai sebagian publikasi ini melaui DIPA FT Unand 2018, (Kontrak No 075/ UN.16.09.D / PL / 2018) 


\section{Daftar Pustaka}

[1] Hazlif Nazif, Muh. Imran Hamid, Pemodelan Dan Simulasi PV-Inverter Terintegrasi Ke Grid Dengan Kontrol Arus "Ramp Comparison Of Current Control", Jurnal Nasional Teknik Elektro, Vol: 4, No. 2, September 2015

[2] Adrianti, Evaluasi Keandalan Pembangkit Listrik Tenaga Surya Yang Terhubung Ke Grid Jurnal Nasional Teknik Elektro, Vol: 5, No. 2, Juli 2016

[3] K.A. Moharram, Enhancing the performance of photovoltaic panels by water cooling, Ain Shams Engineering Journal 4, 869-877, 2013

[4] J. Siecker, A review of solar photovoltaic systems cooling technologies, Renewable and Sustainable Energy Reviews, Vol 79, 192-203, Elsevier, 2017.

[5] Cătălin G.P, Efficiency improvement of photovoltaic panels by using air cooled heat sinks, Energy Procedia 85, 425 - 432, Elsevier, 2016

[6] M. dan E. Yohana, Pengaruh Suhu Permukaan Photovoltaik Module 50 watt peak Terhadap Daya Keluaran Yang Dihasilkan Menggunakan Reflektor Dengan Variasi Sudut Reflektor 0, 50, 60, 70, 80, Jurnal Rolasi, vol. 2, no. 4, pp. 14-18, 2010.
[7] Budi Yuwono, Optimalisasi Panel Sel Surya Dengan Menggunakan Sistem Pelacak Berbasis Mikrokontroler T89C51, FMIPA UNS, Surakarta, 2005.

[8] Foster,Robert, dkk., Solar Energy Renewable Energy and The Environment. Boca Rotan, CRC Press LLC, 2010.

[9] Pitts D. R., and L. E. Sissom, Theory and Problems of Heat Transfer. Second Edition, McGraw-Hill, New York, 2001.

[10] Pane, Ali Hasimi, Modul Perpindahan Panas Konduksi Steady State - One Dimensional, ALP Consultant, Medan, 2015.

\section{Biodata Penulis}

Andi Pawawoi, adalah staf pengajar Jurusan Teknik Elektro Fakultas Teknik Universitas Andalas Padang. Lulus Program Sarjana tahun 1996 pada Bidang Teknik Tenaga Listrik Jurusan Teknik Elektro Fakultas Teknik Universitas Hasanuddin. Pada tahun 2002 menyelesaikan studi program magister bidang Konversi Energi Elekttrik di ITB Bandung

Zulfahmi, menyelesaikan pendidikan Sarjana Teknik Elektro Universitas Andalas tahun 2018. Saat ini bekerja di Trafindo. 